University of Nebraska - Lincoln

DigitalCommons@University of Nebraska - Lincoln

USDA Forest Service / UNL Faculty Publications U.S. Department of Agriculture: Forest Service -National Agroforestry Center

2005

Estimating combustion of large downed woody debris from residual white ash

\author{
Alistair M.S. Smith \\ University of Idaho, alistair@uidaho.edu \\ Andrew T. Hudak \\ Rocky Mountain Research Station, ahudak@fs.fed.us
}

Follow this and additional works at: https://digitalcommons.unl.edu/usdafsfacpub

Smith, Alistair M.S. and Hudak, Andrew T., "Estimating combustion of large downed woody debris from residual white ash" (2005). USDA Forest Service / UNL Faculty Publications. 193.

https://digitalcommons.unl.edu/usdafsfacpub/193

This Article is brought to you for free and open access by the U.S. Department of Agriculture: Forest Service -National Agroforestry Center at DigitalCommons@University of Nebraska - Lincoln. It has been accepted for inclusion in USDA Forest Service / UNL Faculty Publications by an authorized administrator of DigitalCommons@University of Nebraska - Lincoln. 


\title{
Estimating combustion of large downed woody debris from residual white ash
}

\author{
Alistair M. S. Smith ${ }^{\mathrm{A}, \mathrm{C}}$ and Andrew T. Hudak ${ }^{\mathrm{B}}$ \\ ${ }^{A}$ Department of Forest Resources, University of Idaho, Moscow, ID 83844-1133, USA. \\ ${ }^{B}$ Rocky Mountain Research Station, USDA Forest Service, Moscow, ID 83843, USA. \\ Telephone: +1 208883 2327; fax: +1 208883 2318; email: ahudak@fs.fed.us \\ ${ }^{\mathrm{C}}$ Corresponding author. Telephone: +1 208885 1009; fax: +1 208885 6226; email: alistair@uidaho.edu
}

\begin{abstract}
The production of residual white ash patches within wildfires represents near-complete combustion of the available fuel and releases a considerable quantity of gases to the atmosphere. These patches are generally produced from combustion of large downed woody debris (LDWD) such as fallen trees and snags. However, LDWD are generally ignored in calculations of fuel combusted within environments where surface fires dominate (e.g. southern African savannas). To assess the potential of fractional white ash cover as a remotely sensed measure of LDWD combustion, both the proportion of the surface covered by white ash and the combustion completeness required to produce white ash must be quantified. An aerial photograph of woodland savanna fires in north-western Zimbabwe was analysed to estimate the proportion of white ash cover within a typical satellite sensor pixel. The proportion loss on ignition (LOI) of wood samples from the study area was measured and combined with previous estimates of mean tree biomass. The proportion of white ash within the aerial photographs was $0.2 \%( \pm 0.06)$, which corresponded to an additional $67320 \mathrm{~kg} \mathrm{ha}^{-1}$ of biomass combusted above that typically recorded as combusted from a surface fire in this environment $\left(\sim 7000 \mathrm{~kg} \mathrm{ha}^{-1}\right)$. This analysis should be repeated in other savannas and forests, where pre-fire fuel loads and post-fire fractional white ash cover may be higher.
\end{abstract}

Additional keywords: burned area; carbon; emission estimates; loss on ignition; remote sensing; savanna.

\section{Introduction}

Of all the biomes, forests and their associated detritus and soils have the greatest potential to store carbon (Harmon and Marks 2002). Large downed woody debris (LDWD) accounts for at least 10-20\% of forest carbon budgets (Muller and Liu 1991; Turner et al. 1995; Delaney et al. 1998), yet is currently ignored in carbon emission estimates from wildfires (Brown 2002). As such there is an urgent need to quantify the amount and distribution of LDWD at the scale they can be accurately measured on the ground and through high-resolution aerial imagery. The challenge is scaling such estimates to the scale of moderate resolution satellite pixels (i.e. 10-500 m), which remains the most cost-effective approach to assessing the extent of fires, especially those that are large and occur in remote areas (Zhang et al. 2003).

Regional studies assessing biomass combusted (and carbon volatilized) within wildfires have generally been based on extrapolated relationships between remotely sensed measures of the area burned and field measurements of fuel and fire characteristics (Kasischke and Bruhwiler 2003). A considerable body of past research has investigated the application of remote sensing techniques to measure burned area (e.g. Pereira 1999; Smith et al. 2002; Hudak and Brockett 2004), but larger uncertainties continue in the field characterizations of fuels (Kasischke and Bruhwiler 2003). In particular, prefire biomass density and the proportion of fuel combusted are highly variable across small spatial extents (Keane et al. 2001).

In both savanna woodlands and forests, combustion of LDWD leaves a ghost log, or white ash residue in the shape of the former log on a black ash background (Fig. 1). Where combustion is incomplete following wildland fires, vegetation is typically covered in a black carbon residue termed char or black ash (Robinson 1991); where combustion is complete, white mineral ash remains (Stronach and McNaughton 1989). Following forest fires, the spatial density of white ash patches has been observed to increase with increased fire severity (Hudak et al. 2004). Similarly after savanna fires, a greater abundance of white ash has been observed to correspond to a higher pre-fire fuel load (Landmann 2003). Therefore, a measure of white ash per unit area could be considered a quantitative indicator of LDWD combusted. Furthermore, 

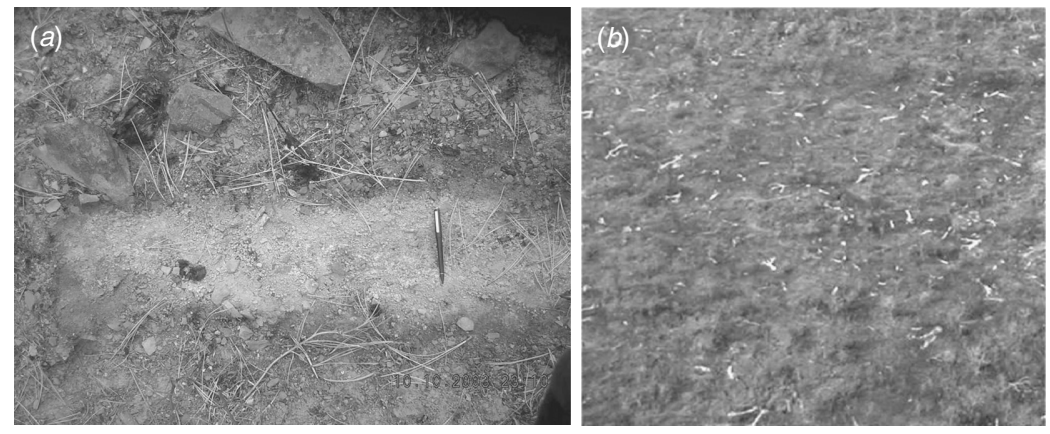

Fig. 1. Production of white ash from LDWD in a southern African woodland savanna at the scale of an $(a)$ individual log, or 'ghost log', and $(b)$ oblique digital aerial photograph showing white LWDW deposits on a black ash background in north-western Zimbabwe. Photograph covers an area $\sim 120 \mathrm{~m} \times 60 \mathrm{~m}$ in size, equating to $\sim 4 \times 2$ Landsat Thematic Mapper pixels.

the albedo (i.e. brightness) of the post-fire surface could indicate pre-fire fuel load, combustion completeness, and mass of carbon volatilized, although white ash assessment must be prompt as it is quickly removed by meteorological processes following fires (Robinson 1991). Quantification of the spatial variation and density of white ash could also be used to parameterize emissions models by providing a spatial measure of the biomass combusted and thus gases volatilized within burned areas (Kasischke and Bruhwiler 2003).

This paper provides a preliminary assessment of the quantity of LDWD combusted per unit area burned in a southern African woodland savanna, using estimates of both the typical cover fraction of white ash and the combustion completeness required to produce such white ash.

\section{Methods}

\section{Study area and aerial imagery}

Eight small $(5 \mathrm{~m} \times 5 \mathrm{~m})$ experimental fires were carried out in woodland savanna sites of light-moderate canopy cover in Chobe National Park (CNP), north-eastern Botswana, at the end of the 2001 dry season (16-22 October 2001). Vegetation in this landscape consisted of an open woodland savanna matrix interspersed with pockets of open grassland. The main species were the grass Dactyloctenium giganteum and the tree Baikiaea plurijuga (Smith et al. 2005). A preliminary assessment of the proportion of white ash within a neighboring (within $90 \mathrm{~km}$ ) savanna woodland in north-western Zimbabwe that burned under similar conditions was assessed using a single digital aerial photograph. This photograph had an approximate spatial resolution of $30 \mathrm{~cm}$ and was acquired 19 October 2000 . A subset of $\sim 120 \mathrm{~m} \times 60 \mathrm{~m}(\sim 4 \times 2$ Landsat Thematic Mapper pixels) was randomly selected within the burned area (Fig. 1b) and used within this preliminary analysis. The white ash patches in the aerial photograph were segmented using simple DN thresholding, and their cumulative area summed, in order to determine the proportion of white ash. The DN threshold (205) was selected as the value at which the presence of the background was visibly minimized, while the majority of the white ash from LDWD remained.

\section{Fuels and loss on ignition measurements}

The available fine fuel load (i.e. excluding LDWD) within each experimental plot was estimated by clipping the herbaceous biomass within five $0.25 \mathrm{~m} \times 0.25 \mathrm{~m}$ quadrats (randomly selected from within a firebreak $2 \mathrm{~m}$ wide surrounding each experimental plot) to the soil level. Five additional post-fire samples were collected at fixed points within each plot. Samples of white ash (collected beside a fallen, combusted tree) and uncombusted woody debris were collected and processed for loss on ignition (LOI).

Proportion LOI was measured following the procedure of Stronach and McNaughton (1989). Each white ash and wood sample was weighed and placed in a muffle furnace for $12 \mathrm{~h}$ at $100^{\circ} \mathrm{C}$, then reweighed to obtain dry fuel mass. Samples were then reheated to $500^{\circ} \mathrm{C}$ in the same furnace for another $18 \mathrm{~h}$ to reduce them to incombustible mineral ash. The samples were then removed from the furnace and rapidly reweighed, to minimize reabsorption of atmospheric moisture. Proportion LOI of each sample was then calculated using Eqn (1):

$$
L O I=\frac{\left(\text { Mass Pre-Furnace }- \text { Mass }_{\text {Post-Furnace }}\right)}{\text { Mass Pre-Furnace }} .
$$

Biomass of fallen trees was estimated using mean values across all woody species, previously measured in the same savanna vegetation type in eastern Botswana (Tietema 1993).

\section{Results}

In the experimental burn plots, fine fuel loads varied between 2000 and $9930 \mathrm{~kg} \mathrm{ha}^{-1}$ and the typical quantities of fuel combusted (excluding LDWD) varied between 937 and $7370 \mathrm{~kg} \mathrm{ha}^{-1}$. These results resembled those from previous studies in similar environments (Table 1). The proportion LOI of the white ash collected from the combusted fallen tree 
Table 1. Mean fine fuel loads combusted in southern African savanna fires

\begin{tabular}{llcrl}
\hline Location & Environment & Load $\left(\mathrm{kgha}^{-1}\right)$ & Combusted (\%) & Reference \\
\hline Botswana & Savanna grassland & $2000-9930$ & $65 \pm 21$ & Smith et al. $(2005)$ \\
South Africa & Savanna parkland & $6500-10000$ & $\sim 56 \pm 14$ & Landmann $(2003)$ \\
Zambia & Dambo grassland & $2220-5950$ & $64 \pm 38$ & Hely et al. $(2003)$ \\
Zambia & Flood plain grassland & $3640-4690$ & $50 \pm 24$ & Hely et al. $(2003)$ \\
Zambia & Semi-arid Miombo woodland & $5100 \pm 396$ & $88 \pm 2$ & Shea et al. $(1996)$ \\
Zambia & Fallow Chiemene & $7353 \pm 708$ & $71 \pm 5$ & Shea et al. $(1996)$ \\
Zambia & Moist Miombo woodland & $5772 \pm 328$ & $74 \pm 4$ & Shea et al. $(1996)$ \\
South Africa & Savanna parkland & $3892-7084$ & $87 \pm 5$ & Shea et al. $(1996)$ \\
\hline
\end{tabular}

was virtually zero (i.e. $<0.1 \mathrm{~g}$ from a sample of $30 \mathrm{~g}$ ). The proportion LOI of unburned wood was $0.88( \pm 0.10)$.

The average proportion of white ash cover measured in the aerial photographs was $0.2 \%( \pm 0.06)$. This estimate of fractional white ash cover was used to estimate LDWD consumed within the extent of the photos.

Approximately $55( \pm 15)$ individual fallen trees were identified within a $\sim 60 \mathrm{~m} \times 60 \mathrm{~m}$ area in the aerial photograph (lower half of Fig. 1b), which translates to a fallen tree density of $\sim 153$ trees ha ${ }^{-1}$. The mean biomass of each tree was estimated to be $500 \mathrm{~kg}$, as measured by Tietema (1993).

By combining this information, a preliminary measure of the tree fuel load combusted per ha was obtained:

$$
T F L=L O I_{T} \times \operatorname{Load}_{T} \times \rho_{T(\text { Fallen })},
$$

where $L O I_{T}$ was the mean loss on ignition of the trees (i.e. wood $=0.88$ ), $\operatorname{Load}_{T}$ was the mean biomass load of each tree (i.e. $500 \mathrm{~kg}$ ), and $\rho_{T \text { (Fallen) }}$ was the fallen tree density (i.e. 153 trees ha ${ }^{-1}$ ).

The calculated TFL $=67320 \mathrm{~kg} \mathrm{ha}^{-1}$ thus approximated the upper limit of LDWD combusted in this woodland savanna. This measurement exceeded by nearly 10 -fold the combusted fine fuel load $\left(\sim 7000 \mathrm{~kg} \mathrm{ha}^{-1}\right)$ measured by Smith et al. (2005) and others (Trollope et al. 1996; Brown 2002; Table 1). This upper limit of LDWD combusted equates to potential upper bounds of $6059 \mathrm{~kg}$ and $1683000 \mathrm{~kg}$ of additional fuel combusted within single Landsat Thematic Mapper (30 $\mathrm{m}$ spatial resolution) and MODIS (500 m spatial resolution) pixels respectively.

\section{Discussion}

This result demonstrates that accurate assessment of fractional white ash cover may be crucial for accurately estimating emissions from such fires. Remote quantification of the spatial density and distribution of residual white ash cover could greatly reduce current uncertainties in the spatial density and distribution of LDWD, and their consequent carbon (and nitrogen) pyrogenic emissions. The wide-scale assessment of LDWD via the detection of white ash by DN thresholding of aerial photography will, however, be limited by the ability to discriminate such white ash patches from bright soils or salt pans, exposed rock outcrops, solar illumination conditions, and sensor characteristics such as the spatial-resolution of the imagery and the type of sensor applied (i.e. digital or film cameras). In addition, DN thresholding is an arbitrary process with the precise DN value requiring reselection with each new image. To potentially overcome such issues, spectral mixture analysis (e.g. Wessman et al. 1997; Drake et al. 1999) or other remote sensing techniques could be applied to quantify white ash fractional cover, provided the imagery is acquired immediately after burning (before wind and water disperse the white ash), and with sufficiently high resolution to feasibly resolve the white ash fraction. Quantifying the white ash fraction and its range of variability from remotely sensed data would then facilitate large-scale estimates of carbon emissions from wildland fires that could be corrected for the presence of combusted LDWD. Such remote estimates could also enable large-scale fuel load reduction and snag production estimates, which are currently necessary for numerous fire management users.

\section{Conclusions}

The white ash collected for LOI analysis was mineral ash produced through the near-complete combustion of a fallen tree. The proportion LOI of unburned wood indicated that $88 \%$ (on average) of the wood biomass is volatilized to produce white ash. Although white ash patches were found to cover only $0.2 \%$ (on average) of the ground surface, the LDWD indicated by these patches may constitute $>90 \%$ of the total pyrogenic emissions in this woodland savanna. These results highlight the need for field and remotely sensed surveys to quantify the pre-fire density and distribution of LDWD, and the post-fire density and distribution of residual white ash patches. Such data may prove critical for accurately estimating pyrogenic emissions and balancing the carbon budget in woodland savannas and forests.

\section{Acknowledgements}

Alistair Smith was supported by the NERC/GANE Thematic Program studentship (NER/S/R/2000/04057). Alistair Smith and Andrew Hudak are part of the Forest Public 
Access Resource Center (ForestPARC), an Upper Midwest Aerospace Consortium (UMAC) group.

\section{References}

Brown S (2002) Measuring carbon in forests: current status and future challenges. Environmental Pollution (Barking, Essex: 1987) 116 363-372. doi:10.1016/S0269-7491(01)00212-3

Delaney M, Brown S, Lugo AE, Torress-Lezama A, Bello Qunitero N (1998) The quantity and turnover of dead wood in permanent forest plots in six life zones of Venezuela. Biotropica 30, 2-11.

Drake NA, Mackin S, Settle JJ (1999) Mapping vegetation, soils, and geology in semi-arid shrublands using spectral matching and mixture modeling of SWIR AVIRIS imagery. Remote Sensing of Environment 68, 12-25. doi:10.1016/S0034-4257(98)00097-2

Harmon ME, Marks B (2002) Effects of silvicultural practices on carbon stores in Douglas-fir-western hemlock forests in the Pacific Northwest, U.S.A.: Results from a simulation model. Canadian Journal of Forest Research 32, 863-877. doi:10.1139/X01-216

Hely C, Alleaume S, Swap RJ, Shugart HH, Justice CO (2003) SAFARI-2000 characterization of fuels, fire behaviour, combustion completeness and emissions from experimental burns in infertile grass savannas in western Zambia. Journal of Arid Environments 54, 381-394. doi:10.1006/JARE.2002.1097

Hudak AT, Brockett BH (2004) Mapping fire scars in a southern African savannah using Landsat imagery International Journal of Remote Sensing 25, 3231-3243. doi:10.1080/01431160310001632666

Hudak AT, Morgan P, Stone C, Robichaud P, Jain T, Clark J (2004) The relationship of field burn severity measures to satellite-derived Burned Area Reflectance Classification (BARC) maps. American Society for Photogrammetry and Remote Sensing Annual Conference Proceedings [CD-ROM], pp. 96-104.

Kasischke ES, Bruhwiler LP (2003) Emissions of carbon dioxide, carbon monoxide, and methane from boreal forest fires in 1998. Journal of Geophysical Research 108, 8146.

Keane RE, Burgan R, van Wagtendok J (2001) Mapping wildland fuels for fire management across multiple scales: integrating remote sensing, GIS, and biophysical modeling. International Journal of Wildland Fire 10, 301-319. doi:10.1071/WF01028

Landmann T (2003) Characterizing sub-pixel Landsat ETM+ fire severity on experimental fires in the Kruger National Park, South Africa. South African Journal of Science 99, 357-360.
Muller RN, Liu Y (1991) Coarse woody debris in an old-growth deciduous forest in the Cumberland plateau, southeastern Kentucky. Canadian Journal of Remote Sensing 21, 1567-1572.

Pereira JMC (1999) A comparative evaluation of NOAA/AVHRR vegetation indexes for burned surface detection and mapping. IEEE Transactions on Geoscience and Remote Sensing 37, 217-226. doi:10.1109/36.739156

Robinson JM (1991) Fire from space: Global fire evaluation using infrared remote sensing. International Journal of Remote Sensing 12, 3-24

Shea RW, Shea BW, Kauffman JB, Ward DE, Haskins CI, Scholes MC (1996) Fuel biomass and combustion factors associated with fires in savanna ecosystems of South Africa and Zambia. Journal of Geophysical Research 101, 23 551-23 568. doi:10.1029/95JD02047

Smith AMS, Wooster MJ, Powell AK, Usher D (2002) Texture based feature extraction: application to burn scar detection in Earth Observation satellite imagery. International Journal of Remote Sensing 23, 1733-1739. doi:10.1080/01431160110106104

Smith AMS, Wooster MJ, Drake NA, Perry GLW, Dipotso FM (2005) Fire in African savanna: testing the impact of incomplete combustion on pyrogenic emissions estimates. Ecological Applications 15, 1074-1082.

Stronach NRH, McNaughton SJ (1989) Grassland fire dynamics in the Serengeti ecosystem, and a potential method of retrospectively estimating fire energy. Journal of Applied Ecology 26, 1025-1033.

Tietema T (1993) Biomass determination of fuelwood trees and bushes of Botswana, Southern Africa. Forest Ecology and Management 60 , 257-269. doi:10.1016/0378-1127(93)90083-Y

Trollope WSW, Trollope LA, Potgieter ALF, Zambatis N (1996) SAFARI-92 characterization of biomass and fire behavior in the small experimental burns in Kruger National park. Journal of Geophysical Research 101, 23 531-23 539. doi:10.1029/96JD00691

Turner DP, Koerper GJ, Harmon ME, Lee JJ (1995) A carbon budget for forests of the conterminous United States. Ecological Applications 5, 421-436.

Wessman CA, Bateson CA, Benning TL (1997) Detecting fire and grazing patterns in tallgrass prairie using spectral mixture analysis. Ecological Applications 7, 493-511.

Zhang Y-H, Wooster MJ, Tutabalina O, Perry GLW (2003) Monthly burned area and forest fire carbon emission estimates for the Russian Federation from SPOT VGT. Remote Sensing of Environment 87, 1-15. doi:10.1016/S0034-4257(03)00141-X 